\title{
Intensive Management of New Hampshire and Giriraja Chickens for Generating Premium Cash Income
}

\author{
D. Neupane, M. Karki and S.B. Shrestha \\ Swine and Avian Research Program, Nepal Agricultural Research Council (NARC) \\ Khumaltar, Nepal \\ e-mail: damodarneypane@yahoo.com
}

\begin{abstract}
Comparative performance of New Hampshire and Giriraja breeds of chicken was studied at Swine and Avian Research Program, Khumaltar. The data on feed intake, weight gain and mortality of the chicks were recorded up to 12 weeks of age. All the experimental birds were reared with commercial broilers feed (Pancha Ratna feed) under similar management. Significant $(<0.01)$ effect of breed on body weight was observed with Giriraja showing superior to New Hampshire. Effect of sex on body weight was also found significant $(\mathrm{P}<0.01)$. At twelve-week of age, higher body weight was observed for Giriraja male (2082 g) followed by Giriraja female (1655 g), New Hampshire male (1338 g) and New Hampshire female (1051 g) with cumulative FCR of 3.40,3.78,3.87 and 3.90 respectively. Irrespective of sex, Giriraja exhibited better FCR than New Hampshire at all weeks of rearing. The cumulative mortality was found as $6.21 \%$ and $12.25 \%$ for New Hampshire and Giriraja respectively. Up to 12 weeks of rearing, higher saving per bird was observed in Giriraja (Rs132.39) than that of New Hampshire (Rs 67.09). The findings of this study revealed that these dual-purpose breeds have potentiality to be competitive meat producers in intensive management. Giriraja is better than New Hampshire in terms of higher growth, better feed efficiency and saving per birds but need for proper health management particularly in the early growth stage. Looking at the havier body weight with having better feed efficiency and higher saving per bird of 12 week rearing, Giriraja could be the choice of economical viable intensive farming for generating premium cash income whereas New Hampshire appears to be suitable for scavenging and semi- scavenging management.
\end{abstract}

Key words: body weight, dual-purpose, FCR, Giriraja, New Hampshire

\section{Introduction}

In Nepal, chicken rearing has been a traditional and small-scale activity retaining a strong religious, social and economic significance. Small numbers of indigenous chicken rearing in scavenging management was dominating feature of the country before commercial poultry production. Though the eggs and meat of indigenous breed have been highly preferred by consumers, their low productivity these breeds cannot meet the demand (Bhurtel 1995, Sah et al. 2000). Visualizing the need of upgrading indigenous breeds, dual-purpose breeds of chicken were found to introduced in country in early 1960's and consequently in 1970 's the private sector started to import commercial breeds (Bhurtel \& Shaha 2000). For the last decade, the country has experienced an impressive growth of the commercial poultry growing at the rate of $13 \%$ and contributing $4 \%$ to gross domestic product (GDP) of the country (Dhakal 2001). However, the majority of commercial farms in the country are found to be small and scattered focusing mainly for meat production. Bhurtel and Shaha (2000) reported that net profit per broiler bird production was Rs. 23.6 for large farms, while in medium farms it was very low (Rs. 8.6) which was mainly due to lower production cycle, low price of birds, lower FCR and high cost of day-old chicks. This clearly indicated that the boom in commercial poultry appeared to put pressure for 
small and medium farmers to compete with large farmers for the broiler production, as the profitability in poultry farming is positively associated with size of farm. Diversification could be the alternate option for small and medium farmers to minimize risk of competition with larger to certain extent.

New Hampshire and Giriaja are the popular dualpurpose chicken being used massively for backyard rearing in different parts of the country. These dual breeds are found to have well adaptability, resistance to common diseases, thrive well and perform better even in scavenging management (Aryal \& Neopane 1997, Shrestha 2000, Rao 2005) and recommended as suitable and profitable for higher meat and egg production under scavenging and semi-scavenging systems of management (SARP 2010). Though, dualpurpose breeds of chicken are low producer than exotic breeds, they can fetch higher market price due to their meat quality which closely resembles to native chicken. Shrestha et al. (2010) reported market price of Giriraja chicken as Rs 350/kg and the average net profit per bird as Rs 415 up to 70 weeks of rearing under semi-scavenging system of management. Looking at its favorable prospects and potentialities, private sector has initiated to maintain parent stocks of dual-purpose chicken for chicks production and marketing networks have already been established (Shrestha et al. 2010) With increasing easily availability of dual-purpose chicks by private sector, some farmers have already started to raise the chicks under semi-intensive management and getting premium market price. Meanwhile small-scale broiler producers and medium farmers have been showing their keen interest to rear dual-purpose chicken with intensive feeding management in commercial scale. Exploitation of these potentialities, improved feed and management could lead to economically viable alternate breeds for large-scale production. However, most of the information found on these breeds was mainly on low input management. Hence, the objective of this trial was to evaluate the potentialities of the dual-purpose breeds to be suitable for intensive management.

\section{Methodology}

The experiment was carried out at Swine and Avian Research Program, Nepal Agricultural Research Council (NARC), Khumaltar to evaluate the comparative performance of two popular dual purpose breeds of chicken namely New Hampshire (NH) and Giriraja (GR). In this, experiment was started with 204 day-old chicks of both breeds. The birds were randomly divided into three replicate groups of each breed and the above breed were housed in separate compartments. Sexing was done at 5 weeks of age. Commercial available broiler feed (Pancha Ratna) was fed to all the birds from day-old to 12 weeks of age, at which the experiment was terminated. Ample fresh water and uniform standard management were provided to all the birds throughout the experimental periods. Observation on daily feed intake, weekly body weight, and mortality were recorded and weight gain, feed efficiency and relative growth rate percentage was calculated. Minitab statistical package was used for data analysis. Economics of rearing these breeds was also calculated. The actual market price of feed (Rs 26.7, Rs 26.3 \& Rs 25.7 per kg of Feed B1, B2 \& B3), day-old chick costs (Rs 25) and selling price of bird (Rs 175 per kg live weight) were used for economic calculation.

\section{Results and Discussion \\ Feed intake}

A significant $(<0.001)$ effect of breed on daily feed intake (g) was observed during rearing except at the initial first week. Giriraja chicken had higher feed intake than New Hampshire. The differences were found to be subsequently increasing with age. Similarly, male birds exhibited significantly $(<0.01)$ higher feed intake than female birds in all the weeks of rearing. The details of daily feed intake have been presented in Table 1 and 2.

Table 1. Daily feed intake (g) and cumulative feed efficiency $( \pm \mathrm{SE})$ up to 4 weeks of age

\begin{tabular}{c|l|l|l|l|l|l|l|l}
\hline Breed & \multicolumn{4}{|c|}{ Daily feed intake (g) } & \multicolumn{5}{c}{ Curmulative feed efficiency } \\
\hline \multirow{3}{*}{$\mathrm{NH}$} & $1 \mathrm{wk}$ & $2 \mathrm{wk}$ & $3 w \mathrm{k}$ & $4 \mathrm{wk}$ & 1 wk & 2 wk & $3 w \mathrm{k}$ & 4 w \\
& 8.15 & 17.61 & 26.22 & 33.10 & 2.57 & 2.18 & 2.41 & 2.48 \\
& \pm 0.77 & \pm 1.11 & \pm 1.19 & \pm 0.70 & \pm 0.24 & \pm 0.15 & \pm 0.13 & \pm 0.08 \\
$\mathrm{GR}$ & 8.76 & 22.24 & 42.00 & 52.6 & 1.83 & 1.90 & 2.35 & 2.34 \\
& \pm 0.88 & \pm 1.55 & \pm 1.84 & \pm 1.46 & \pm 0.18 & \pm 0.14 & \pm 0.13 & \pm 0.10 \\
P value & 0.143 & 0.002 & 0.000 & 0.000 & 0.001 & 0.003 & 0.071 & 0.011 \\
\hline
\end{tabular}


D. Neupane et al/Intensive Management of New.......

Table 2. Daily feed intake (g) of New Hampshire and Giriraja chicken breeds

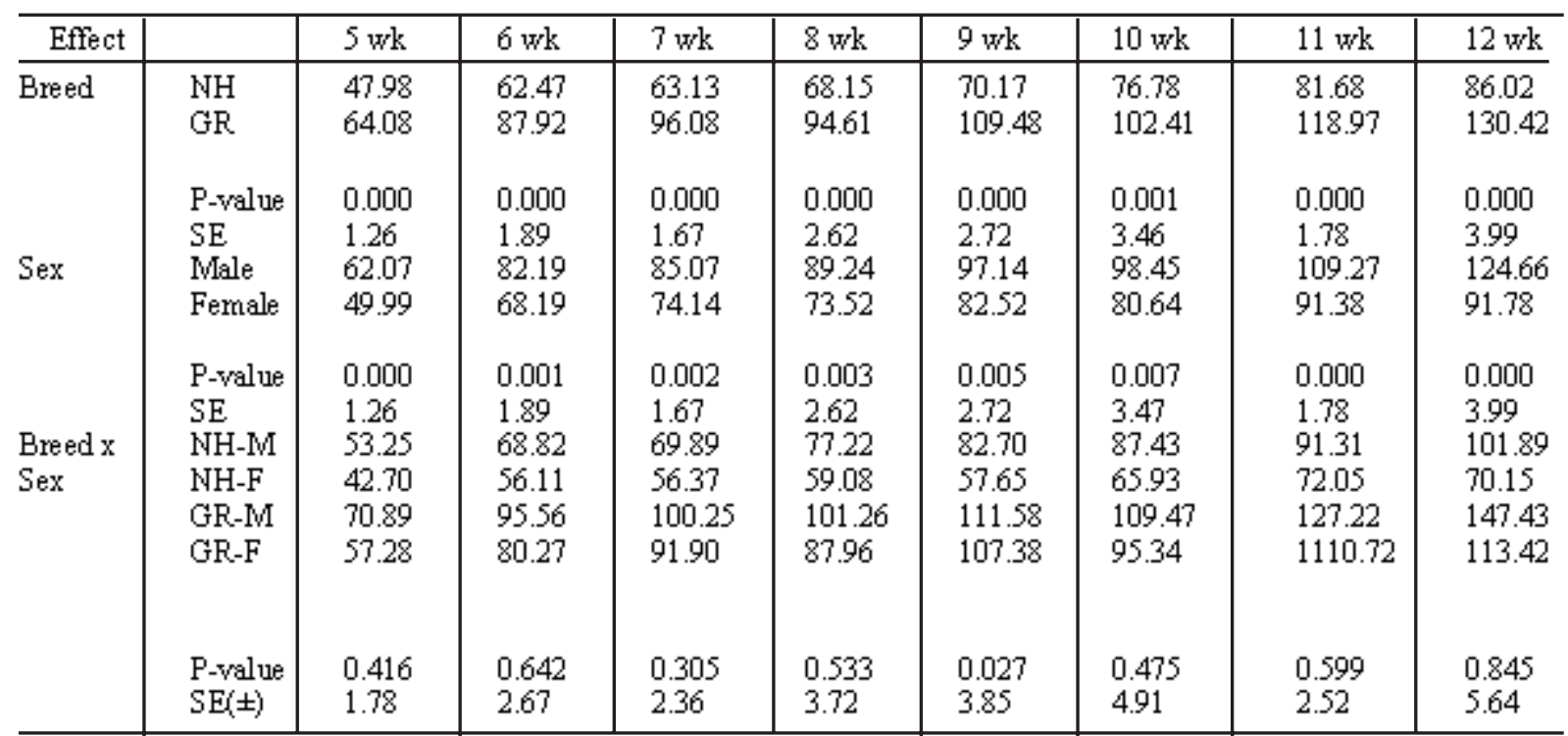

\section{Body weight}

Significant $(<0.01)$ effect of breed on body weight was observed in Giriraja showing superiority over New Hampshire (Table 3). Effect of sex on body weight was also found significant $(\mathrm{P}<0.01)$. The average eightweek body weight of New Hampshire observed in this trial was higher than reported by Aryal et al. (1994), and Aryal and Neopane (1997). But in contrary, the average body weight of Giriraja was lower than the finding of Ramappa and Lokanath (1985) ie 1.37 $\mathrm{kg}$ and $1.47 \mathrm{~kg}$ (Shrestha et al. 2000). In this observation, twelve-week body weight was observed higher in Giriraja male (2082 g), followed by Giriraja female (1655 g), New Hampshire male (1338 g) and New Hampshire female (1051g). Interaction effect of sex and breed on body weight was significant $(<0.05)$ only up to the age of seven weeks.

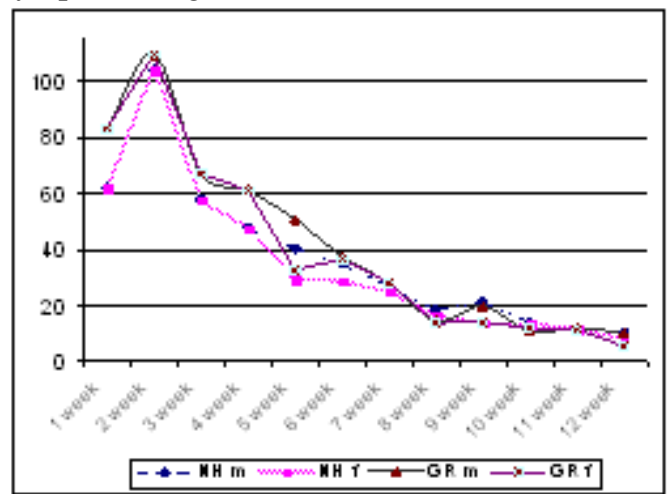

Fig. 1. Interaction effect of sex and breed on body weight.

\section{Relative growth rate}

The relative growth rate percentage of both male and female of New Hampshire and Giriraja are decline with subsequent weeks of rearing except at the two week of age (figure 1). It exceeds more than $106 \%$ an average at two weeks then sharply decline progressively and becoming the figure less than $8.5 \%$ an average at 12 weeks. The lowest growth rate was observed for New Hampshire female $(6 \%)$ followed by Giriraja female (8\%) at twelve weeks of age indicating less economical afterwards for meat production. Karki and Neupane (2008) reported similar trends of RGR\% on broiler chicken. They found highest RGR\% at early period (172\%), then decline subsequently in the subsequent period of rearing and slump down to $28.3 \%$ at seventh week of age, which is the common marketing age of broiler chicken. Karki (2005) observed similar trends of RGR\% on turkey.

\section{Feed conversion}

A significant effect $(<0.05)$ of breed on feed conversion was observed during the whole period of rearing except at three week of age with Giriraja showing better than others. Overall feed conversion ratio(FCR) was slightly deteriorated with advancement of age. Up to eight weeks of age, the mean FCR was observed as 2.9 and 3.3 for Giriraja and New Hampshire chickens. 
Table 3. Mean body weight (g) of New Hampshire and Giriraja chickens

\begin{tabular}{|c|c|c|c|c|c|c|c|c|c|}
\hline Effect & & $5 \mathrm{wk}$ & $6 \mathrm{wk}$ & $7 \mathrm{wk}$ & $8 w \mathrm{k}$ & $9 \mathrm{wk}$ & $10 \mathrm{wk}$ & $11 \mathrm{wk}$ & $12 \mathrm{wk}$ \\
\hline Breed & $\begin{array}{l}\mathrm{NH} \\
\mathrm{GR}\end{array}$ & $\begin{array}{c}372.3 \\
588.8\end{array}$ & $\begin{array}{l}491.8 \\
808.2\end{array}$ & $\begin{array}{l}620.3 \\
1034.9\end{array}$ & $\begin{array}{l}729.2 \\
1184.1\end{array}$ & $\begin{array}{l}859.7 \\
1387.6\end{array}$ & $\begin{array}{l}978.2 \\
1544.7\end{array}$ & $\begin{array}{l}1091.1 \\
1727.8\end{array}$ & $\begin{array}{l}1195.0 \\
1869.0\end{array}$ \\
\hline Sex & $\begin{array}{l}\text { P-value } \\
\text { SE } \\
\text { Male } \\
\text { Fernale }\end{array}$ & $\begin{array}{l}0.000 \\
5.62 \\
507.0 \\
454.1\end{array}$ & $\begin{array}{l}0.000 \\
5.95 \\
693.1 \\
606.9\end{array}$ & $\begin{array}{l}0.000 \\
7.42 \\
884.6 \\
770.6\end{array}$ & $\begin{array}{l}0.000 \\
12.33 \\
1027.8 \\
885.5\end{array}$ & $\begin{array}{l}0.000 \\
14.02 \\
1237.9 \\
1009.4\end{array}$ & $\begin{array}{l}0.000 \\
25.14 \\
1386.6 \\
1136.3\end{array}$ & $\begin{array}{l}0.000 \\
22.90 \\
1550.1 \\
1268.9\end{array}$ & $\begin{array}{l}0.000 \\
26.77 \\
1710.0 \\
1353.0\end{array}$ \\
\hline $\begin{array}{l}\text { Breed } x \\
\text { Sex }\end{array}$ & $\begin{array}{l}\text { P-value } \\
\text { SE } \\
\text { NH-M } \\
\text { NH-F } \\
\text { GR-M } \\
\text { GR-F }\end{array}$ & $\begin{array}{l}0.000 \\
5.62 \\
387.2 \\
357.4 \\
626.7 \\
550.8\end{array}$ & $\begin{array}{l}0.000 \\
5.95 \\
523.0 \\
460.5 \\
863.2 \\
753.2\end{array}$ & $\begin{array}{l}0.000 \\
7.42 \\
664.8 \\
575.8 \\
1104.4 \\
965.4\end{array}$ & $\begin{array}{l}0.000 \\
12.33 \\
787.4 \\
671.1 \\
1268.3 \\
1099.8\end{array}$ & $\begin{array}{l}0.000 \\
14.02 \\
956.0 \\
763.4 \\
1519.8 \\
1255.5\end{array}$ & $\begin{array}{l}0.000 \\
25.14 \\
1089.3 \\
867.2 \\
1683.9 \\
1405.4\end{array}$ & $\begin{array}{l}0.000 \\
22.90 \\
1212.5 \\
969.8 \\
1887.7 \\
1567.9\end{array}$ & $\begin{array}{l}0.000 \\
26.77 \\
1338.0 \\
1051.0 \\
2082.0 \\
1655.0\end{array}$ \\
\hline & $\begin{array}{l}\text { P-value } \\
\text { SE }\end{array}$ & $\begin{array}{l}0.020 \\
7.95\end{array}$ & $\begin{array}{l}0.022 \\
8.41\end{array}$ & $\begin{array}{l}0.044 \\
10.49\end{array}$ & $\begin{array}{l}0.173 \\
17.44\end{array}$ & $\begin{array}{l}0.108 \\
19.83\end{array}$ & $\begin{array}{l}0.450 \\
35.55\end{array}$ & $\begin{array}{l}0.268 \\
32.39\end{array}$ & $\begin{array}{l}0.100 \\
37.86\end{array}$ \\
\hline
\end{tabular}

Table 4. Cumulative feed conversion ration (FCR) of New Hampshire and Giriraja chickens

\begin{tabular}{|c|c|c|c|c|c|c|c|c|c|}
\hline Effect & & $5 \mathrm{wk}$ & $6 \mathrm{wk}$ & $7 w \mathrm{k}$ & $8 w \mathrm{k}$ & $9 \mathrm{wk}$ & $10 \mathrm{wk}$ & $11 \mathrm{wk}$ & $12 \mathrm{wk}$ \\
\hline \multirow[t]{3}{*}{ Breed } & $\begin{array}{l}\mathrm{NH} \\
\mathrm{GR}\end{array}$ & $\begin{array}{l}2.803 \\
2.459\end{array}$ & $\begin{array}{l}3.030 \\
2.558\end{array}$ & $\begin{array}{l}3.120 \\
2.652\end{array}$ & $\begin{array}{l}3.317 \\
2.887\end{array}$ & $\begin{array}{l}3.397 \\
3.032\end{array}$ & $\begin{array}{l}3.542 \\
3.191\end{array}$ & $\begin{array}{l}3.704 \\
3.339\end{array}$ & $\begin{array}{l}3.890 \\
3.592\end{array}$ \\
\hline & P-value & 0.000 & 0.000 & 0.000 & 0.001 & 0.009 & 0.015 & 0.010 & 0.021 \\
\hline & $\mathrm{SE}$ & 0.029 & 0.049 & 0.048 & 0.055 & 0.075 & 0.081 & 0.077 & 0.073 \\
\hline \multirow[t]{4}{*}{ Sex } & Male & 2.582 & 2.755 & 2.850 & 3.074 & 3.110 & 3.283 & 3.443 & 3.638 \\
\hline & Fermale & 2.680 & 2.833 & 2.922 & 3.130 & 3.319 & 3.450 & 3.600 & 3.844 \\
\hline & P-value & 0.047 & 0.292 & 0.324 & 0.499 & 0.086 & 0.181 & 0.187 & 0.083 \\
\hline & $\mathrm{SE}$ & 0.029 & 0.049 & 0.048 & 0.055 & 0.075 & 0.081 & 0.077 & 0.073 \\
\hline \multirow{6}{*}{$\begin{array}{l}\text { Breed } x \\
\text { Sex }\end{array}$} & NH-M & 2.788 & 3.002 & 3.102 & 3.317 & 3.344 & 3.508 & 3.685 & 3.875 \\
\hline & NH-F & 2.817 & 3.058 & 3.138 & 3.316 & 3.450 & 3.576 & 3.723 & 3.905 \\
\hline & GR-M & 2.376 & 2.507 & 2.597 & 2.831 & 2.876 & 3.057 & 3.201 & 3.402 \\
\hline & GR-F & 2.543 & 2.608 & 2.706 & 2.943 & 3.187 & 3.324 & 3.447 & 3.782 \\
\hline & P-value & 0.134 & 0.759 & 0.611 & 0.490 & 0.364 & 0.409 & 0.306 & 0.131 \\
\hline & $\mathrm{SE}$ & 0.042 & 0.069 & 0.069 & 0.078 & 0.106 & 0.114 & 0.108 & 0.103 \\
\hline
\end{tabular}

Similarly, the mean cumulative FCR was observed as 3.59 and 3.89 for Giriraja and New Hampshire, respectively up to 12 weeks of rearing. Up to eight weeks of rearing, Aryal and Neopane (1997) observed 2.8 and 3.68 FCR for Giriraja and New Hampshire, respectively. Similarly, Ramappa and Loknath (1985) reported 2.4 for Giriraja in India that was similar to FCR of commercial broilers in Nepal, i.e. 2.3 to 2.5 (Bhurtel \& Shaha 2000). Effect of sex was found significant $(<0.05)$ only at initial weeks but was observed at par up to $12^{\text {th }}$ week of rearing with male showing slightly better than that of the female. The details of FCR have been shown in Table 4. The table indicated that better FCR was observed for Giriraja male (3.40) followed by Giriraja female (3.78) and New Hampshire male (3.87). 
D. Neupane et al/Intensive Management of New.......

Table 5. Feed cost, gross income and profits from New Hampshire and Giriraja chicken at different weeks of rearing

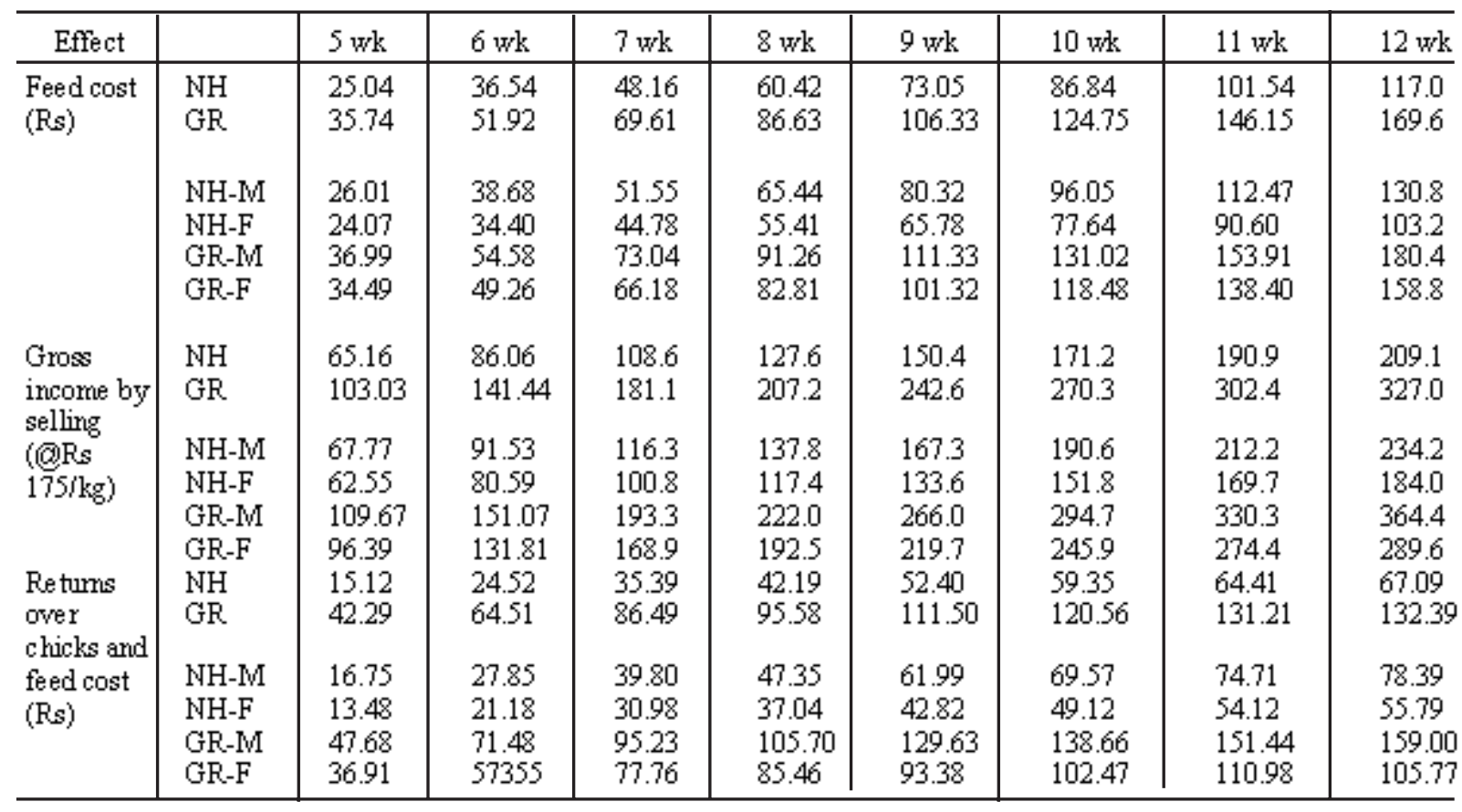

\section{Mortality}

The average mortality up to 4 weeks of age was found lower in New Hampshire (2.35\%) than in Giriraja $(9.1 \%)$. The cumulative mortality up to 12 weeks of rearing was also found as $6.21 \%$ and $12.25 \%$ for New Hampshire and Giriraja, respectively. Aryal and Neopane (1997) observed $12 \%$ and $12.5 \%$ mortality with Giriraja and New Hampshire up to eight weeks of rearing. Similarly, Bhurtel and Shaha (2000) reported mean mortality of $9.6 \%$ and $10.8 \%$ for medium and large size broiler farms in Nepal. Though, Ramappa and Lokanath (1985) reported Giriraja as hardy chicken, the mortality of it was found in our context indicating further need for proper health care and management particularly in the early stage of growth.

\section{Economics}

The details of economics of rearing dual-purpose chickens are given in Table 5, which clearly revealed the higher saving per bird over chicks and feed cost for Giriraja than that of New Hampshire. The average saving per bird was Rs 132.39 and Rs 67.09 at twelve weeks of age. Irrespective of breed, males exhibited higher profit per bird compared to females over the entire periods of rearing. At 12 weeks of age the average was recorded Rs 118.70 and Rs 80.78 for male and female, respectively. Up to 12 weeks of rearing, saving per bird was found higher with Giriraja males (Rs 159.00) followed by Giriraja females (Rs 105.77) and New Hampshire male (Rs 78.39) while lowest saving was recorded for New Hampshire female (Rs 55.79). The findings of the present study revealed that those dual-purpose breeds had potentiality to be competitive meat procedures in intensive management. Giriraja chicken is better than New Hampshire in terms of higher growth, better feed efficiency and saving per birds, but need proper health management in future. Looking at the heaviest body weight with better feed efficiency and higher saving per bird for at 12 week rearing, Giriraja could be the choice for economical viable intensive farming for generating premium cash income whereas New Hampshire appeared to be suitable for scavenging and semi-scavenging management.

\section{References}

Aryal, I.K. and S.P. Neopane. 1997. Performance of Giriraja chicken in the eastern hills of Nepal. PAC technical paper no. 179. Pakhribas Agricultural Centre, Dhnakuta. 14pp. 
Nepal Journal of Science and Technology Vol. 15, No.2 (2014) 23-28

Aryal, I.K., N.P. Shrestha and S.P. Neopane. 1994. Performance of Giriraja chicken at Pakhribas Agricultural Centre. PAC working paper No. 109. Pakhribas Agricultural Centre, Dhnakuta.

Bhurtel, R. and B.K.P. Shaha. 2000. Poultry development in Nepal, constraints and potentialities. Research report 45. Winrock International, 51pp.

Bhurtel, R. 1995. Production performances of local chicken in midhills and plains of Nepal. In: Proceeding of the second National Animal Science Convention, 7-10, August,1995, Lalitpur. Pp.119123.

Dhakal, S. 2001. Chitwan provides a model of the poultry industry's growth in the country. Spotlight weekly. www.nepalnews.com.np/spotlight/2001/jan05/ national9.htm

Karki, M. 2006. Growth, efficiency of feed utilization and economics of different rearing periods of turkeys. Nepal Agriculture Research Journal 6:8085.

Neupane, D. and M. Karki. 2008. Effect of herbal liver stimulant (Livoliv) on the feed consumption, FCR, weight gain and economics of commercial broilers. Paper presented at the Second Convention of Society of Agricultural Scientists, Nepal.

Ramappa, B.C. and Lokanath, G.R. 1985. Giriraja, a miracle fowl for villagers/tribals. Department of Poultry Science, University of Agricultural Sciences, Hebbal Campus, Banglore.
Rao, S.V.R. 2005. Backyard poultry farming- a boon to alleviate protein hunger in rural india. Poultry articles. www.poulvet.com/poultry particles backyard_farming.php

Sah, R.B., P. Mandel and R.S. Mandel.2000. Information on the native chicken raised in the eastern Terai region of Nepal. In: Proceeding of the fourth national workshop on livestock and fisheries research in Nepal, (24-26, April 2000), Pakhribas (Eds. S.P. Neopane, A.K. Rai and R. Bhurtel). Pp.65-71.

SARP. 2010. Annual report of Swine and Avian Research Programme (2009/10), Khumaltar, Kathmandu, Nepal.

Shrestha, S.B., P. Mandal and R.B. Sah. 2004. Studies on production traits in Giriraja chicken. In: Proceedings of the sixth national workshop on livestock and fisheries research 1-2 july, 2004.Pp21-24.

Shrestha, S.B., J.N. Pradhan, R.K. Karki, T.P. Paudel and T.S.Dhaubhadel.2010. Evaluation of production performance of Giriraja chicken in Dolakha. In: Proceeding of the ninth national outreach workshop (7-8 June 2010), NARC, Kathmandu. Pp 352-357.

Shrestha, S.B., S.M. Pradhan and M. Karki. 2011. Rearing of Giriraja chicken to increase farm income and improving livelihoods of small farmers of Jiri, Dolakha. Paper presented at the Sixth Convention of the National Animal Science Association, Nepal held during 25-25 sept,2011 at Jawalkhel, Lalitpur, Nepal. 